\title{
VIDEOACTIVISMO Y NUEVOS MOVIMIENTOS URBANOS EN ESPAÑA
}

\author{
Francisco Sierra Caballero* \\ David Montero Sánchez**
}

\begin{abstract}
Resumen. El presente artículo analiza desde la economía política las funciones de la comunicación y la cultura en los actuales procesos de redefinición territorial y marketing urbano. Frente a este fenómeno, el texto aborda críticamente las formas de videoactivismo surgidas desde los nuevos movimientos urbanos en España, atendiendo a las tensiones presentes en estos espacios de resistencia cultural donde, a pesar de todo, se siguen materializando el conflicto, la diferencia y las contradicciones implícitas en las formas subalternas de acción colectiva. Dicha exploración trata de comprender los patrones de interacción entre nuevas formas de ciudadanía y la apropiación del espacio público a través de ejercicios de autoorganización que reconecten con la complejidad de las formas urbanas de sociabilidad.
\end{abstract}

Palabras Clave. Videoactivismo, marketing urbano, democracia, movimientos sociales, capitalismo cognitivo

\section{INTRODUCCIÓN}

Las tendencias o cambios sociales que introduce la denominada "sociedad de la información" redefinen en la actualidad de forma determinante los procesos de desarrollo cultural en la construcción de la ciudadanía y en la generación de espacios democráticos (Mattelart, 2002). La comunicación y la cultura se ven alteradas por una reconfiguración general de lo público que exige de la investigación una concepción más praxiológica

\footnotetext{
* Catedrático acreditado de Teoría de la Información en la Universidad de Sevilla. Correo electrónico: fsierra@us.es

** Es profesor e investigador postdoctoral Juan de la Cierva en la Universidad de Sevilla. Correo electrónico: davidmontero@us.es
} 
de las mediaciones en la era digital. La proliferación de iniciativas de marketing urbano (véase Paddison, 1993) y de proyectos de redefinición territorial en auge, como los modelos de ordenación de las ciudades del conocimiento o los tecnopolos (en parte impulsados por las propias industrias culturales), plantea de hecho la necesidad de una nueva agenda que comience por pensar las nuevas prácticas creativas de comunicación emergentes (Sierra y Martínez, 2012). Más aún cuando se observa en debates contemporáneos como el relativo a la llamada economía creativa, un proceso intensivo de articulación del sector de la comunicación con realidades apenas consideradas por los estudios comunicológicos como la ordenación del espacio, la promoción del turismo o la concepción de los imaginarios urbanos y las manifestaciones culturales autóctonas como fuente de acumulación de capital (UNESCO, 2013; Sierra, 2014).

En las siguientes páginas se abordan los principales ejes que convergen en la configuración del espacio público hoy día de cara a cartografiar distintas experiencias videoactivistas en España y determinar el papel que han desempeñado estas experiencias como focos de resistencia cultural y fuentes de acción colectiva local en el contexto de los nuevos movimientos urbanos. De forma más específica, buscamos establecer hasta qué punto estas prácticas videoactivistas favorecen nuevas narrativas de la distopía urbana en relación con procesos de autogestión en la vida cotidiana, en lo que David Harvey denomina ciudades rebeldes (Harvey, 2012).

Partiendo de la aportación realizada por la economía política como marco teórico de base, el texto realiza en primer lugar un análisis crítico del papel instrumental que están jugando la comunicación y la cultura en los procesos de redefinición del espacio público promovidos desde la lógica del marketing urbano. Dicho recorrido presta especial atención a fenómenos como la concepción de la comunicación como eje de sutura del tejido social de las ciudades, la emergencia de nuevos espacios de aglomeración urbana y su valor cultural y, por último, la persistencia de profundas asimetrías interurbanas. Frente a esta "comodificación" del espacio, defendemos un enfoque totalizador que visibilice las fórmulas creativas de resistencia, diferencia y conflicto que hoy día hacen frente a la creciente homogeneización y desterritorialización de las ciudades dentro del marco general de subsunción de la vida entera por el capital. 
Desde esta línea de análisis, el texto se acerca a las prácticas videoactivistas que se han venido desarrollando en España durante los últimos años, en buena parte como respuesta a procesos acelerados de valorización y redefinición del entorno urbano. Más concretamente, nuestro universo de estudio remite a ejercicios videoactivistas que, por su temática o planteamientos, inciden en conflictos asociados con la reivindicación y la defensa del espacio público, tanto en cine y vídeo como, más recientemente, mediante el uso de las nuevas formas de autonomía que ofrece el medio digital. Los criterios que sistematizan esta exploración apuntan a cuatro líneas de acción básicas que emergen del análisis empírico: la reivindicación de memorias espaciales amenazadas por las nuevas lógicas culturales; la irrupción de la ciudad como espacio en constante conflicto; la ocupación de espacios de producción de cara a instaurar circuitos culturales alternativos; y, por último, la remezcla subversiva de materiales visuales con el objetivo de exponer la superficialidad de las prácticas culturales asociadas al marketing urbano.

Hablamos por lo tanto de la práctica videoactivista como radicalmente democrática no sólo en tanto que dispositivo de reconstrucción de la ciudad como escenario de intercambio, sino también como ejercicio de creación y resistencia que recurre a nuevas herramientas de autoorganización social. El videoactivismo, fuertemente relacionado con los movimientos sociales, aparece así como un punto de partida desde el que reflexionar sobre las características de una cultura radical-democrática (Montero y Moreno, 2014).

\section{REDES DE COMUNICACIÓN Y DESTERRITORIALIZACIÓN URBANA}

Uno de los efectos más importantes del capitalismo — según nos recuerda François Loyer - es la transformación de la escala de los proyectos de construcción y reorganización del espacio. De lo local a lo global, del Estado-nación a la economía-mundo, la historia del capitalismo es la historia de la ampliación y modificación de las condiciones espaciotemporales de desarrollo social (Santos, 1978). Esta lógica, en el ámbito de la comunicación, se traduce en la alteración de los parámetros espaciotemporales, introduciendo lo que podríamos denominar "lo espectacular 
integrado" (Debord, 2003). La industria cultural es deudora de esta querencia del capitalismo por ampliar sus territorios, por modificar la magnitud y monumentalidad de sus edificaciones, por apreciar lo extraordinario como principio de su evolución social (Abril, 2000; Sierra, 1998). Tanto es así que, en parte como resultado de lo que Giddens denomina "fenómeno de desanclaje" prototípico de la modernidad, podríamos afirmar que a mayor escala del capitalismo, mayor influencia de la comunicación. En nuestros días, esta lógica se traduce en la popularización de fenómenos como el marketing urbano, que asigna a la publicidad y a las estrategias de proyección de la imagen pública de las ciudades la compleja tarea de posicionamiento y desarrollo económico del espacio social o, en suma, del conjunto del territorio y de la cultura local (Florida, 2009; Sierra, 2009).

Esta tendencia general a integrar territorios, procesos y formas culturales que tradicionalmente la modernidad había compartimentado según un principio de pensamiento bárbaro y simplificador (Edgar Morin dixit) es hoy trascendida por una nueva lógica relacional, obligándonos a pensar, por ejemplo, la comunicación y la educación junto a relaciones entre el sector de las industrias culturales, el desarrollo económico y la organización territorial (Sierra, 2001). En este contexto, los proyectos de desarrollo endógenos se transforman en la marca de una ciudad al tiempo que la representación del conflicto depende de la función de valorización del capital y de las necesidades impuestas por la economía internacional sobre los territorios y culturas autóctonas (Harvey, 2014; Observatorio Metropolitano, 2015). Parafraseando al profesor George Yúdice, se activa un modo de pensamiento que obedece a la racionalidad instrumental y piensa la cultura solo como recurso para esta necesidad de modernización económica y social (Yúdice, 2002). Esta dinámica es propia de lo que convenimos denominar capitalismo cognitivo, un nuevo modelo de acumulación determinado por la información y el conocimiento, por el trabajo inmaterial y la captura o cercamiento del código, en el que se tiende a descentralizar y desterritorializar la cultura y las dinámicas de reproducción social a escala local (Boutang et al, 2004). Así, en las últimas décadas, se observa una tendencia notoria hacia la descentralización, que privilegia el ámbito local como eje estratégico de las transformaciones y cambios necesarios ante el complejo mundo interconectado de la socie- 
dad global a partir de la creatividad y talento autóctono (YPRODUCTIONS, 2009). Este fenómeno forma parte de un proceso contradictorio del capitalismo por el que la creciente autonomía de lo local tiene lugar en una lógica de reorganización de las economías de escala que obliga a los actores sociales a un intensivo proceso de desterritorialización y reterritorialización de sus espacios, instituciones y comunidades. Así,

las metrópolis expresan e individualizan el consolidarse de la jerarquía global, en sus puntos más articulados, en un complejo de formas y ejercicio de comando. Las diferencias de clase y la programación genérica en la división del trabajo ya no se hacen más entre naciones sino entre centro y periferia, en la metrópolis (Negri, 2006: 241).

En este proceso, las nuevas expresiones de la cultura popular deben ser revisitadas no como formas o manifestaciones ancladas de experiencia, sino como formas dinámicas y fugaces de representación que tradicionalmente la teoría marxista había asociado a la superestructura y que hoy constituyen formas materiales transformadoras del proceso histórico, y la base material de definición del capitalismo postfordista o cognitivo (Berardi, 2003). Así, la ciudad digital bascula en una contradicción o paradoja compleja. En una cultura en la que todo habitar es provisorio, un puro efecto de flujo, "la ciudadanía se obtiene por trasmigración, por recorrido y conversión. No se pertenece a una comunidad u otra por origen o estancia, se tiene la marca instantánea del circular, del encuentro fortuito" (Brea, 2007: 109). En este escenario debe analizarse la microfísica de potentes procesos productivos de subjetividad que surcan el nuevo entorno urbano, así como las formas contemporáneas de movilización y acción colectiva, como veremos en el caso del videoactivismo.

El problema es cómo se teorizan esos cambios. Mientras que cierto posmodernismo "conservador" insiste en la necesidad de olvidar las vanguardias estéticas, teóricas y el pensamiento totalizador al analizar la nueva cuestión urbana, otros planteamientos, como defendemos desde una perspectiva económico-política, reconocen como pertinente la tesis que vincula la imagen de la ciudad con la lógica de la subsunción que proyecta la economía de signos y espacios de la que habla Scott Lash 
(Jameson, 2005; Lash/Urry, 1998). Desde esta perspectiva, la mercadotecnia de las ciudades cumple la función mediadora de comodificación que procura no tanto ampliar los espacios de convivencia como la manifestación más desarrollada de la creciente reificación característica del capitalismo tardío, en la que el conjunto social y el territorio conforman una mercancía global.

\section{CRÍTICA TEÓRICA Y CUESTIÓN URBANA}

Frente a las concepciones neoconservadoras y posmodernistas de la arquitectura y la ciudad, David Harvey advierte que tenemos otras alternativas críticas que podríamos retomar como estrategia teórica a la hora de pensar la ciudadanía, la comunicación y la cultura urbana. Si adoptamos este marco teórico-crítico, pensar la cultura digital y la ciudad tiene implicaciones desde el punto de vista de la economía política, en la medida en que integra aspectos del desarrollo urbano que van más allá de los que fijaba la visión clásica de lo público en la modernidad, pues concierne a aspectos sustantivos de lo que hoy debemos entender por ciudadanía según puede observarse en algunas experiencias emblemáticas de reestructuración urbana como la ciudad de Londres (Sierra, 2013). Desde este punto de vista, todo análisis global de los nuevos movimientos urbanos y el papel de la comunicación en la acción colectiva y en la reconfiguración mercantil de la cultura local pasa por repensar la naturaleza mediatizada del capitalismo flexible y posmoderno. Para ello es necesario generar un pensamiento totalizador a modo de condición necesaria para analizar las contradicciones y desarrollar modelos de planeación del desarrollo ciudadano en la era red de forma más equilibrada y democrática, a partir de la propia experiencia de las nuevas subjetividades emergentes y sus manifestaciones culturales. Esto exigiría, en principio, abordar tres aspectos problemáticos en la nueva cultura digital:

1. El pancomunicacionismo. Los modelos de ciudad-red o ciudades digitales reeditan hoy el común error de pensar la realidad del territorio desde visiones comunicocéntricas o más exactamente desde el pancomunicacionismo entendido como espacio de remediación que recurre a 
la práctica comunicacional. Se afirma así, como criticara en los ochenta Bernard Miège, la falsa idea de que es en el ámbito exclusivo de la comunicación donde las ciudades y en general los territorios resolverán sus contradicciones, falencias y retos para el desarrollo endógeno y la definición de una nueva ciudadanía (Miège, 1992). La ciudad digital deviene, en este sentido, una suerte de ciudad de frecuencia modulada. Si modular es imponer una ruptura, una discontinuidad, separar y dividir la unión cooperativa espontánea, así como gestionar y gobernar las formas de vida urbana, la era de la ciudad informacional depende hoy más que nunca de la comunicación y de la capacidad expresiva de los sujetos sociales creativos para poner en común su capital simbólico. Del malestar de la cultura y del malestar de las ciudades se pasa así a la tonificante idea de la garantía de capitalización sociocultural que procuraría el recurso a la comunicación y la cultura como espacio de representación. Es a través de ellas como se re-articulan las identidades fracturadas, derivadas de las licuaciones y la disolución de las ataduras simbólicas, físicas y sociales que la rotación acelerada del capital produce (Bauman, 2001). Por ello, como sugiere Jameson, es necesario vincular lo simbólico con el desarrollo del capitalismo, es decir, no podemos entender la arquitectura posmoderna, el inconsciente ideológico, sin la trama material que la gobierna. Resulta imprescindible entender que la economía de signos está sujeta a la dinámica de circulación, que lo simbólico forma parte ya de nuestra estructura económica y que está sujeto por tanto a las leyes de desarrollo del capitalismo (Lash; Urry, 1998).

2. La emergencia de nuevos espacios. La crítica fundada al fetichismo mercantilista de las nuevas formas de pancomunicacionismo no puede, no obstante, ignorar que asistimos a la configuración y desarrollo de nuevos espacios públicos y formas de urbanidad que han alterado los modelos y las experiencias subjetivas de ciudadanía, afectando consecuentemente a la cultura y a las lógicas de representación y conocimiento social (Innerarity, 2006; Sennett, 2000). Las plazas comerciales, las ciudades dispersas y los nuevos espacios de aglomeración urbana dan cuenta de un nuevo marco lógico en el que pensar la política de comunicación municipal y más allá aún, las fórmulas teóricas y críticas de negación del modelo privativo de adaptación o comodificación de lo urbano. Pen- 
sar críticamente la ciudadanía y la mediación en la nueva cartografía urbana significa, en coherencia, redefinir la noción del espacio público como una dimensión externa, estática y cosificada, asumiendo una cultura y una concepción de la comunicación como proceso instituyente desde abajo, que aflora sobre todo en los desbordes creativos de los nuevos actores o sujetos sociales.

3. La ciudad total, el pensamiento global. La constatación de la hipótesis de Scott Lash sobre el dominio de jerarquías territoriales entre zonas vivas y ciudades muertas confirma, como hemos avanzado al comienzo, el dominio de unas condiciones materiales de reproducción de las asimetrías interurbanas en las que la comunicación juega la función ideológica de reproducción y legitimación de las formas idealistas de pensamiento de la cultura posmoderna. Ello es así inexorablemente, mal que pese a los ingenuos urbanistas de las ciudades soñadas. Esta misma recurrente fe idealista ha llevado a los estudios en la materia a una concepción insular y fragmentaria de las transformaciones territoriales cuando más necesario es, a nuestro juicio, un enfoque globalizador (Harvey, 2003).

Esto solo es posible desde un acercamiento crítico que capture la singularidad de los procesos creativos de la multitud conectada de las nuevas metrópolis en función de una teoría del cambio social potente y reflexiva. De este modo se podría contribuir a la consecución de un nuevo pensamiento que resitúe la práctica teórica en el marco general de las actuales transformaciones en curso. Los trabajos, por ejemplo, de Mattelart sobre la arqueología y genealogía de la comunicación moderna demuestran cómo la génesis del campo de la comunicación establece una cierta relación entre las formas de poder y control y las formas de conocimiento, fraguando las formas idealistas de concepción de la ciudadanía que hoy es necesario repensar desde otra mirada de lo social al abordar la cuestión urbana con los nuevos movimientos sociales en red.

\section{VidEOACTIVISMO Y NUEVOS IMAGINARIOS URBANOS}

En la mayoría de las experiencias conocidas de planeación de la política de comunicación urbanística, las mediaciones simbólicas son pensadas 
por lo tanto, y casi exclusivamente, como un dispositivo de reconstrucción de la imagen interna que busca crear identidad colectiva como ciudad y, desde luego, atraer nuevas inversiones. Para ello se reduce la capacidad de autodeterminación de los actores locales. Se testan igualmente formas de privatización del espacio público sobre la base de una férrea división del trabajo entre quienes proyectan los imaginarios y el conjunto de la ciudadanía, convertida en figurante y consumidor del espectáculo creativo de la nueva ciudad. Sin embargo, frente estas nuevas dinámicas, han venido emergiendo prácticas que buscan visibilizar los espacios de sombra alejados de los nuevos focos culturales. Aquí la ciudad aparece como entidad contestada, en constante conflicto y en la que colisionan diferentes memorias y concepciones de la vida en comunidad. Se trata de ejercicios culturales de distinta factura que reivindican la ciudad más allá de su fachada de cartón piedra, en un esfuerzo creativo que, a base de resituarse continuamente en los márgenes de la industria cultural, está alumbrando nuevas formas de producción en los ámbitos de la comunicación y la cultura.

En este contexto, la mediación audiovisual, bien sea a través del cine, vídeo, televisión u otras prácticas multimedia, aparece como espacio privilegiado de resistencia urbana, en particular a medida que los distintos avances tecnológicos han hecho posible la aparición de circuitos de comunicación alternativos a la gran industria audiovisual. El término videoactivismo entronca así con una tradición de utilización de la comunicación para el cambio social que, más allá del mero compromiso político, adquiere una dimensión emancipadora tanto a nivel de contenido (cine guerrilla, utilización táctica de los medios, acciones contrainformativas) como en la forma (vídeo participativo, sin autoría, patrones de colaboración on-line). En ambos casos, el videoactivismo alude a un movimiento de abajo a arriba, desde las calles a los espacios de poder a nivel local; lejos de aparecer como meros figurantes del espectáculo urbano, en estas prácticas el plano de la representación se sitúa al nivel de las reivindicaciones ciudadanas, convirtiendo el ejercicio audiovisual en un espacio desde el que escenificar nuevas formas de ciudadanía cultural (Van Zoonen, Vis y Mihelj, 2010).

A pesar de contar con un importante recorrido histórico, la discusión académica en torno al videoactivismo es aún escasa y carece de 
ejes conceptuales definidos desde los que categorizar fenómenos como la emergencia de una cultura participativa audiovisual on-line o la compleja intersección de procesos de (contra)vigilancia que atraviesan servicios como Bambuser. Algunas contribuciones, sin embargo, nos permiten delimitar el videoactivismo como práctica radical en tanto que aparece irremisiblemente unido a fórmulas de acción política y cambio social (Bustos, 2006), elaboradas en su afán discursivo (Askanius, 2012) y profundamente relacionadas con los nuevos movimientos urbanos (Galán Zarzuelo, 2012). En gran medida es una lectura que coincide con Mateo y Rajas (2014) cuando definen el videoactivismo como "prácticas sociales de carácter comunicativo que son utilizadas como recursos de intervención política por actores ajenos a las estructuras de poder dominantes (sujetos de contrapoder)" (2014), aunque cabría recalcar que buena parte del ejercicio videoactivista se dedica hoy día a la visualización de los espacios de sombra del poder, más que a ejercer como contrapoder efectivo.

Partiendo de esta delimitación conceptual, nuestro trabajo empírico realiza un análisis discursivo de las formas en las que el videoactivismo en España ha puesto en pie una visión alternativa de la ciudad frente a la creciente importancia de los procesos de apropiación simbólica del espacio urbano por parte de las lógicas propias del capital. Nuestro interés en este recorrido no es tanto el de profundizar en cada una de las propuestas, sino que más bien buscamos aportar los ejes discursivos que ha venido generando la práctica videoactivista en relación con las dinámicas exploradas en los apartados anteriores. Para ello, nos hemos centrado en las obras que más claramente abordan la temática de la transformación y la especulación del espacio público, haciendo especial hincapié en aquellas que se enmarcan en líneas de acción concretas que buscan contribuir de forma definida a un cambio social específico.

En definitiva, nuestro objetivo con este recorrido es definir algunas ideas-fuerza en torno a las cuales confluyen los itinerarios del videoactivismo actual en España a partir de su relación con la ciudad. A continuación, resumimos algunas de estas ideas fundamentales:

1. Reivindicación de memorias espaciales. Temáticamente, una parte significativa de los ejemplos de videoactivismo urbano analizados privilegia 
los puntos de articulación que vinculan las historias de vida con el espacio colectivo y ambos a su vez con las lógicas alienantes de un capital implacable con la periferia. La ciudad aparece en muchos de estos ejercicios como una agregación de lugares comunes, espacios de localización de dinámicas sociales, de consumos y formas de habitar singulares. Los pliegues de esta cultura monumental se actualizan y se someten a una lógica crítica de reinterpretación, recuperando el espesor matricial de las culturas, lugares y experiencias de los sujetos para recuperar los espacios de esperanza y su potencial imaginario. Se opta pues por retratar los lugares de convivencia tradicional, no en un ejercicio nostálgico sino con el afán de exponer la amenaza bajo la que se encuentran los procesos de intercambio social que estos espacios generan y en los que se integran los mundos de vida de los protagonistas y sus recuerdos. Hay que apuntar que esta veta videoactivista aparece de forma prevalente en una parte significativa de los ejercicios que tienen a la ciudad de Barcelona como protagonista a consecuencia de lo que Mari Paz Balibrea denomina "los profundos cambios, tanto socioeconómicos como urbanísticos, que la ciudad sufre desde la mitad de los años 70" (Balibrea, 2004) y que siguen jugando un papel fundamental en la política local barcelonesa con la llegada del nuevo siglo.

Mención especial merece entre las producciones videoactivistas más recientes el trabajo desarrollado en los últimos años por la productora independiente Metromuster en Barcelona. Trilogia de dones lluitadores (2009), [No res] Vida i mort d'un espai en tres actes (2012) o Ciutat morta (2014) son sólo algunos de los títulos en los que la relación entre memoria y ciudad se asocia con frentes de resistencia cultural y activismo específicos. En el primero de estos filmes, se aborda la vida cotidiana de los habitantes de la Colònia Castells, colonia fabril situada en el barrio de Les Corts, como espacio reapropiado por la ciudadanía, que han convertido las casas bajas en uno de los pocos espacios horizontales de la ciudad frente a la amenaza inminente del plan de expropiación y derribo municipal. En la Trilogia de dones lluitadores (2009), los espacios en resistencia son aún más concretos (bares y comercios tradicionales en el centro urbano) cuyos propietarios de toda la vida, ya mayores, establecen lazos con los movimientos sociales como única estrategia para mantener vivos los recuerdos asociados a estos establecimientos. 
Aún más evidentes son estos lazos en Ciutat morta ${ }^{1}$ que explora de forma mucho más explícita el conflicto entre el proyecto de marketing urbano y reconstrucción de Barcelona con el acoso a identidades contraculturales que no se subsumen fácilmente en los mismos. Aquí los intereses urbanísticos, la corrupción y la marketización de la ciudad de cara sobre todo al turismo, juegan una parte importante en el suicidio de Patricia Heras, encarcelada de forma injusta tras un altercado en los alrededores de un teatro ocupado que acabó con un agente sin casco en coma por un impacto. En el recuerdo de la poetisa Patricia Heras se contienen distintas formas de vida amenazadas, que entran en conflicto directo con los patrones de valorización del espacio urbano, un conflicto que obtiene réplica visual en las imágenes de una de las amigas de Patricia que grita a través de un megáfono su rabia en la vía pública, reivindicando su propio derecho a ser en una ciudad cada vez menos pensada al nivel de sus habitantes.

Cabe señalar que, mediante esta movilización de la memoria urbana no se pretende tanto reivindicar lo local como defender el derecho a la periferia, al espacio alejado de los criterios de valoración impuestos por los distintos proyectos de redefinición del territorio. Este es el caso también del trabajo del realizador catalán Jacobo Sucari en cintas como Poblenou: la lluita per l'espai urbà (2006) o Destruir y construir, historia de una fábrica (2011), también con Barcelona como telón de fondo, o de títulos como Bartolo. Un documental sur realista (Pitu García y David Aguilar, 2007), que gira en torno al bar del mismo nombre en el barrio de La Casería, en San Fernando, o de A ras de suelo (Alberto García Ortiz y Agatha Maciaszek, 2007) sobre el barrio de Lavapiés en Madrid.

2. La ciudad contestada. Frente al principio de traducción basado en la subsunción de formas de sociabilidad y los espacios a los que éstas se aso-

\footnotetext{
${ }^{1}$ Ciutat Morta supone el primer caso de ejercicio videoactivista de amplio éxito y repercusión en España. La película disecciona el caso de corrupción judicial del 4F. Lanzado en 2013, ha sido exhibido extensamente en espacios públicos y multitud de centros con un amplio eco social, mientras que a nivel institucional logró su presencia fuera de concurso en el Festival de Cine de San Sebastián de 2014; se hizo con el premio al mejor documental en el Festival de Cine de Málaga 2014 y obtuvo menciones honoríficas en varios festivales de documental.
} 
cian, también encontramos en las imágenes del videoactivismo contemporáneo una necesidad de hacer evidente el choque, la fricción que estas dinámicas homogeneizadoras encuentran en la reivindicación radical de lo popular desde una dinámica distópica. Son imágenes que dan cuerpo a una cultura del malestar que encuentra su expresión más directa en la oposición rebelde a la utopía urbana. Aquí, lejos de remediar las heridas abiertas en las ciudades por los procesos de especulación, el objetivo principal es el de visualizar fórmulas de confrontación. Por la pantalla desfila una galería de subjetividades y espacios alternativos reconstruidos más allá de cualquier lógica de valorización propuesta por el capital, no ya desde la reivindicación de la memoria a la que aludíamos en el punto anterior, sino desde el conflicto directo como eje de la resistencia frente a la redefinición del espacio público. Es el caso, por ejemplo, de varios de los documentales dedicados a recoger la experiencia de espacios ocupados en diferentes ciudades de España: Casas Viejas (Asamblea del CsOA Casas Viejas, 2006) y Londres no es Sevilla (Mariano Agudo, 2010), sobre el centro social ocupado "Casas Viejas" en el barrio del Pumarejo de Sevilla; Laboratorio 3. Ocupando el vacío (Kinowo Media, 2007), Okupa. Crónica de una lucha social (Octavi Royo e Ignasi P.Ferré, 2008) u Okupación (Christopher Patz, 2011).

De esta forma, el videoactivismo relocaliza los puntos cardinales de la ciudad mediante los conflictos que se abren en la misma, las más de las ocasiones en respuesta a proyectos de espectacularización del espacio urbano. Es el caso de títulos como Oscuros portales (Falconetti Peña, 2011), El Forat (1998-2004) (Falconetti Peña, 2004), Irubide (Eguzki Bideoak, 2007), A Tornallom (Enric Peris, 2005), ¿De quién es la calle? (Francotiradores del vídeo, 2005), Espanish Dream (Guillermo Cruz y Santiago Cirugeda, 2009) o El cielo está enladrillado (Videometrópolis, 2007). Un documental como Gamonal (ES) (Álvaro Alonso de Armiño, 2008) puede considerarse como representativo de esta veta temática del videoactivismo urbano contemporáneo en España. Por un lado, explora la identidad de un pueblo transformado en barrio obrero a partir del crecimiento de la ciudad de Burgos, hasta adoptar un rol periférico en los planes de desarrollo urbano. Aquí el vínculo entre el pasado y el presente se construye a partir de las luchas frente a los proyectos urbanísticos que desdibujan la marcada identidad del barrio. Luchas 
que de hecho cristalizarían varios años después de la realización de este documental en un conflicto abierto provocado por la decisión del Ayuntamiento de Burgos de gastar 13 millones de euros de la partida de urbanismo para construir un bulevar sobre uno de los principales ejes del barrio. ${ }^{2}$ De hecho, las prácticas videoactivistas contemporáneas entroncan en esta vertiente con una importante tradición de luchas vecinales surgida en España durante las últimas décadas del franquismo y cuyos referentes audiovisuales son filmes como El largo viaje hacia la ira (Llorenç Soler, 1969), La ciudad es nuestra (Tino Calabuig y Miguel Ángel Condor, 1975) o La lucha vecinal (Colectivo Cine de Clase, 1976).

Es también en el seno de esta ciudad en conflicto donde se articula de forma más evidente la ligazón entre la singularidad de las luchas y los conflictos asociados al espacio urbano y la necesidad de colocar estas en relación directa con el marco de juego totalizador en el que han devenido las lógicas del capital. Las luchas que tienen lugar en el espacio urbano se interiorizan a nivel identitario, dando lugar a subjetividades transformadas que, en la oposición al proceso de redefinición urbana que les marginaliza, obtienen nuevas razones de ser. Destellos de este tipo de reflexión son ya visibles en propuestas audiovisuales como El taxista ful (Jordi Solé, 2005). En la falsa historia verdadera de José, de 52 años, que robaba taxis para poder trabajar con ellos y ahora espera para ingresar en la cárcel con la única ayuda de varios activistas sociales, encontramos un filme en el que la subjetividad contestataria se negocia a golpe de incoherencia y marginación en las calles de Barcelona. José, al igual que los espacios en los que desarrolla su vida, se ve abocado a una marginación creciente y a un desplazamiento del espacio público que da como resultado su encuentro con los nuevos movimientos urbanos, de los que desconfía pero con los que comparte la defensa de los espacios que conforman la geografía de su existencia. En su planteamiento visual, la película busca multiplicar la incidencia de los espacios sin valor de cambio evidente, pero profundamente in-

\footnotetext{
${ }^{2}$ Las protestas tuvieron lugar en Gamonal entre el 10 y el 17 de enero de 2014, con manifestaciones por parte de varios cientos de vecinos con el objetivo de paralizar las obras puestas en marcha por el ayuntamiento. Las protestas se saldaron con 46 detenidos y varios heridos por ataques a sucursales bancarias y quemas de contenedores. En diversas ciudades de España se dieron manifestaciones de apoyo a los vecinos de Gamonal.
} 
tegrados en la cultura popular de la ciudad como los únicos refugios posibles para su protagonista. La cultura de la resistencia aparece aquí como espacio generador de subjetividades.

La misma lógica que asocia espacio y generación de subjetividades subversivas está presente en una propuesta audiovisual muy distinta. En los vídeos que generan las acciones del colectivo "Flo6x8" (http://www. flo6x8.com/), ${ }^{3}$ por ejemplo, el flamenco recupera su raíz como forma del comentario social, lo que le devuelve su fuerza como manifestación cultural directamente conectada con las vivencias de las clases populares. Las actuaciones de cante y baile se desarrollan aquí siguiendo una lógica de protesta situacionista (Blissett, 2000), en el espacio de la sucursal bancaria en un gesto claramente oposicional (desafiante, incluso), que busca evidenciar la presencia del sujeto y su capacidad para construir cultura en un espacio donde "tan sólo es posible actuar como un consumidor" (Becker, Hernández y Werth, 2012: IX y X).

3. Ocupar el audiovisual. Como explica Elisenda Ardevol en relación con el trabajo de Metromuster en el filme [No res] Vida i mort d'un espai en tres actes (2012), más allá de su contenido, la realización de la película se constituye en sí misma como un acto de activismo, dado que "el proceso mismo de producción se inscribe en movimientos sociales más amplios" (Ardevol, 2013: 29). Se trata de un reconocimiento de la práctica cultural más allá de una dimensión simbólica inmediata y de la lógica de la mercancía para repensar críticamente desde los parámetros de la economía política de la comunicación la posibilidad de generar procesos culturales autónomos, que visibilicen la existencia de prácticas culturales alternativas a los circuitos de valorización puestos en juego por las instituciones municipales. La puesta en marcha y el desarrollo de estos proyectos buscan en consecuencia generar comunidad en torno a los mismos desde una lógica de prototipado (Corsin y Estalella, 2011) que deviene en una propuesta alternativa a los mecanismos de producción, difusión y consumo convencionales. Las formas y tensiones

${ }^{3}$ El colectivo Flo6X8 se ha hecho famoso en España por sus actuaciones de cante y baile flamenco, con letras adaptadas, en diversas sucursales bancarias mientras estás desarrollan su actividad. El lema que utilizan es "cuerpo contra capital". 
que estructuran cada proyecto tienden a materializarse en ámbitos como la gestión de derechos de autor (donde las licencias "creative commons" adquieren un carácter irrenunciable) y en la implicación de actores institucionales que pueden ir desde televisiones (por ejemplo, TV3 y su participación en la posproducción de [No res]) a entidades públicas como consejerías, museos o servicios de cultura municipales, sobre todo.

Se tiende, sin embargo, a generar modelos alternativos que visualicen posibilidades de resistencia a cada paso. Así se observa, por ejemplo, una tendencia a la puesta en marcha de mecanismos de financiación alternativos como el crowdfunding mediante plataformas específicas para proyectos audiovisuales (kifund.com), la producción cultural (verkami. com) o más generales como lanzanos.com o goteo.org. Este es el caso de la propia [No res] o de varios de los proyectos de vídeo comprendidos bajo el paraguas de $15 \mathrm{~m} . c c$, como los documentales 15m. Málaga despierta (2013) o 15m: Excelente. Revulsivo. Importante (2012), que combinan la autofinanciación con el crowdfunding. Dicho compromiso condiciona igualmente las fórmulas de difusión que incluyen medios para devolver el resultado final con la publicación abierta en Internet, proyecciones gratuitas en distintas ciudades y las mencionadas licencias creative commons. Igualmente, en ámbitos como la difusión, colectivos como "La Hamaca" o "Eguzki Bideoak" llevan ya varios años promoviendo canales alternativos centrados en espacios de artivismo y vídeo de contenido político.

Sería ingenuo sin embargo obviar que también existen relaciones con organizaciones empresariales al uso e incluso corporaciones que pueden apropiarse de los valores de creación comunitarios que están presentes y en los que se basan muchas de estas iniciativas. Tal y como ya han puesto de relieve algunos autores, no son pocas las ocasiones en que corporaciones del ámbito de la información y la comunicación on-line obtienen réditos monetarios y simbólicos directos del trabajo realizado en comunidades colaborativas sin ánimo de lucro (Fuster Morell, 2011).

4. Vídeos de remezcla política y sátira urbana. En un entorno cultural fuertemente dominado por la pulsión de la remezcla (Manovich, 2007), debemos hacer notar que el vídeo on-line ha aparecido en los últimos años 
como una estrategia privilegiada para las prácticas que buscan desactivar las imágenes de la utopía urbana: una práctica que privilegia la sátira y el humor como estrategias de resistencia política. Desde las campañas promocionales de ayuntamientos y autoridades locales, a los mensajes celebratorios de los medios masivos, las posibilidades de reconfiguración propias del vídeo distribuido facilitan una práctica material directa sobre las imágenes dialéctica y dialógica, que reconfigura los mensajes, los cortocircuita y recontextualiza, con el objetivo de desenterrar contradicciones, incoherencias y paradojas, haciendo visibles valores ideológicos que no son identificables para el espectador en un primer momento.

Es el caso, por ejemplo, de algunos de los trabajos de la artista sevillana María Cañas. En su obra Sé Villana (La Sevilla del Diablo) (2013) la memoria de la ciudad, en este caso Sevilla, y sus prácticas culturales se yuxtaponen al espectáculo urbano de proyectos como la Torre Pelli, ${ }^{4}$ cuyas imágenes conviven igualmente con extractos de El coloso en llamas (John Guillermin, Irwin Allen, 1974) y con la ocupación de otro entorno espectacularizado (Metropol-Parasol, popularmente conocido como Las Setas) por activistas del 15m. De igual forma, las imágenes del noticiario franquista No\&Do que declaran la desaparición del asentamiento chabolista de El Vacie en Sevilla, resuenan entre las imágenes de familias en situación de pobreza y los vídeos promocionales de la Expo '92 como evento universal que da entrada a Sevilla al espacio de las grandes ciudades europeas. Aquí, más allá de cualquier mensaje concreto es el propio gesto emancipador de reapropiación de la imagen, de puesta en cuestión, el que adquiere un tono radical directamente asociado con la cultura popular. Colectivos como Zemos'98 (http://www.zemos98.org/, La Casinegra (http://lacasinegra.com/) y artistas como Malaventura (http://malaventura.net/), entre otros, ofrecen algunos ejemplos de este tipo de vídeos poniendo en evidencia algunas lecciones de la experiencia de análisis durante nuestro trabajo de campo.

\footnotetext{
${ }^{4}$ La Torre Pelli, financiada por la entidad bancaria Cajasol antes de 2008, representa a nivel simbólico varios de los males de la crisis, especialmente a nivel local. La mega construcción de esta torre la convierte en el edificio más alto de Andalucía, así como el séptimo rascacielos más alto de España. La torre incluso provocó que la UNESCO considerase replantearse el estatus de Sevilla como patrimonio de la humanidad dado el impacto visual de la misma en el perfil de la ciudad.
} 


\section{CONCLUSIONES}

Hasta el momento, el debate académico sobre la cultura y su papel en la configuración de los espacios públicos apenas ha reconocido el papel de esta como eje transversal que da sentido a una nueva configuración de la ciudad informada por lógicas de valorización del territorio que, lejos de respetar su complejidad, le otorgan un valor simbólico e identitario que diferencia el entorno urbano en procesos de competencia global por recursos como el turismo o las inversiones en infraestructura. Nuestra investigación pone de relieve no sólo la importancia de realizar una lectura de estos fenómenos desde la economía política de la comunicación, sino que también especifica los ejes que sostienen este fenómeno de instrumentación cultural: el recurso al pancomunicacionismo como herramienta de sutura de los conflictos urbanos, la emergencia y valor cultural de nuevos espacios de aglomeración y, por último, la constatación de nuevas asimetrias interurbanas maquilladas por una utilización de la cultura como recurso y sancionada por un ejercicio investigador fragmentario.

Frente a estas dinámicas, el videoactivismo se presenta a sí mismo como una reivindicación de la periferia territorial, como una reconexión con la complejidad de las formas de sociabilidad urbana vigentes hasta hace poco tiempo. Curiosamente, es la propia centralidad del concepto "imagen" en las propuestas identitarias que se desprenden de las estrategias de marketing urbano la que propicia que sea en el ámbito de la comunicación audiovisual donde una construcción crítica de la praxis cultural sea más fácilmente rastreable. En las imágenes del videoactivismo, la ciudad emerge como forma del procomún, ágora posible, espacio reapropiado y barrios en resistencia, determinando una veta discursiva que supone una parte integral de los itinerarios que determinan un nuevo modelo de desarrollo urbano en comunicación.

Además, la cultura audiovisual activista dibuja la ciudad como el terreno de juego en el que se evidencian, por un lado, la subsunción de cualquier espacio bajo la lógica del valor añadido, material y simbólico; y, por otro, tanto las acciones de reapropiación desde las que emergen nuevas fórmulas de ciudadanía que defienden la pervivencia de personas, lugares, asociaciones y celebraciones en claro peligro de extinción. 
En este sentido, la práctica videoactivista urbana va mucho más allá del mero producto propagandístico y apunta a una lógica de pensamiento que evidencia las rupturas y discontinuidades espacio-tiempo que dan como resultado la fragmentación de mundos de vida en su relación con el entorno. Igualmente, buena parte del valor de resistencia de estas prácticas estriba en su afán de abrir caminos alternativos a las vías tradicionales de producción, distribución y consumo cultural regidas por el beneficio y la propiedad cerrada de los derechos intelectuales. Se persigue una política prefigurativa que pretende transformar los ejercicios de videoactivismo no únicamente en artefactos discursivos críticos, sino en elementos que aglutinan comunidades de pensamiento y acción, que demuestran con sus actividades que es posible hackear los circuitos de la industria cultural reactualizando así, en cierto modo, el legado de la guerrilla comunicativa desplegada décadas atrás por el situacionismo.

\section{BibLIOGRAFÍA CONSULTADA}

AbriL, G. (2000), Teoría General de la Información. Datos, relatos y retos. Madrid: Cátedra.

Ardevol, E. (2013), "Cultura digital y prácticas creativas. Tientos etnográficos en torno a la cultura libre", en Internet Interdisciplinary Institute (IN3). Barcelona: Universitat Oberta de Catalunya.

Askanius, T. (2014), "Video for Change", en K. G. Wilkins, T. Tufte, y R. Obregon, Handbook of Development Communication and Social Change. Wiley-Blackwell, pp. 453-470.

Balibrea, M. P. (2004), "Barcelona: del modelo a la marca", en Desacuerdos. Artículo disponible en línea: http://public.citymined. org/KRAX_CARGO/teoria/modelo_barcelona/Barcelona, \%20 del\%20modelo\%20a\%20la\%20marca, \%20desacuerdos.pdf (consulta: 23 de septiembre de 2015)

Bauman, Z. (2001), La posmodernidad y sus descontentos. Madrid: Akal.

Becker, F. N., Hernández, P. y Werth, B. (2013), Imagining Human Rights in Twenty-First Century Theater: Global Perspectives. Londres: Palgrave McMillan. 
Berardi, F. (2003), La fábrica de infelicidad. Nuevas formas de trabajo y movimiento global. Madrid. Traficantes de Sueños.

Blissett, L. (2000), Manuel de Guerrilla de la Comunicación. Madrid: Virus Editorial.

Boutang, Y. M., et al. (2004), Capitalismo cognitivo, propiedad intelectual y creación colectiva. Madrid: Traficantes de Sueños.

BREA, J. L. (2007), Cultura RAM. Barcelona: Gedisa.

Bustos, G. (2006), Audiovisuales de combate. Acerca del videoactivismo contemporáneo. Buenos Aires: La Crujía.

Corsin, A. y Estalella, A. (2011), "\#spanishrevolution", en Anthropology Today, 27, 4. pp. 19-23.

Debord, G. (2003), La sociedad del espectáculo. Valencia: Editorial Pretextos.

Florida, R. (2009), Las ciudades creativas. Barcelona: Paidós.

Fuster Morell, M. (2011), "The Unethics of Sharing: Wikiwashing", en W. Sützl \& F. Stalder (coords.), International Review of Information Ethics: Special issue: Ethics of Sharing, vol. 15. Artículo en línea disponible en: http://www.i-r-i-e.net/inhalt/015/015-Morell.pdf, (consulta: 15 de mayo de 2014).

Galán Zarzuelo, M. (2012), "Cine militante y videoactivismo: los discursos audiovisuales de los movimientos sociales", en Revista Comunicación 1 (10), pp. 1091-1102.

Giddens, A. (2008), Consecuencias de la Modernidad. Madrid: Alianza Editorial.

HaRvey, D. (2003), Espacios de esperanza. Madrid: Akal. (2012), Rebel Cities: From the Right to the City to the Urban Revolution. New York: Verso.

(2014), 17 contradicciones y el fin del capitalismo. Quito: IAEN.

InNerarity, D. (2006), El nuevo espacio público. Madrid: Espasa-Calpe.

JAMEson, F. (2005), El posmodernismo o la lógica cultural del capitalismo avanzado. Buenos Aires: Paidós.

Lash, S. y J. UrRy (1998), Economía de signos y espacios. Buenos Aires: Amorrortu.

Negri, T. (2006), "La multitud y la metrópoli", en Revista Brumaria, no. 6, Madrid. 
Manovich, L. (2007), "What Comes After Remix?". Artículo en línea disponible en: http://remixtheory.net/?p=169 (consulta: 15 de octubre de 2014).

Mateos, C. y Rajas, M. (2014), "Videoactivismo, la resistencia política cámara en mano: conceptos y rasgos", en J. Sierra Sánchez y F. García García (coords.), Tecnología y narrativa audiovisual. Madrid: Fragua.

Mattelart, A. (2002), Historia de la Sociedad de la Información. Barcelona: Paidós.

Mı̇̇GE, B. (1992), La sociedad conquistada por la comunicación. Barcelona: ERP-PPU.

Montero, D. y Moreno, J. M. (2014), El cambio social a través de las imágenes. Madrid: Los Libros de la Catarata.

Observatorio Metropolitano (2015), El mercado contra la ciudad. Globalización, gentrificación y políticas urbanas. Madrid: Traficantes de Sueños.

Paddison, R. (1993), "City Marketing, Image Reconstruction and Urban Regeneration", en Urban Studies, 30 de marzo, pp. 339-349.

Santos, M. (1978), O espaço dividido: os dois circuitos da economia urbana. Río de Janeiro: Livraria Francisco Alves.

Sennett, R. (2000), La corrosión del carácter. Barcelona: Anagrama.

SierRA, F. (1998), Elementos de Teoría de la Información. Sevilla: Editorial MAD. (2001), "Navegaciones y migraciones culturales. Lógicas sociocomunicativas en la sociedad del conocimiento", en Sphera Pública. Revista de Ciencias Sociales y de la Comunicación, no. 1, Universidad Católica de San Antonio, Murcia, pp. 135-153. (2009), Cambio urbano y desarrollo local. Una perspectiva crítica de la comunicación. Santiago de Compostela: usc/Cidacom. y Martínez, M. (eds.) (2012), Comunicación y desarrollo. Prácticas comunicativas y empoderamiento local. Barcelona: Gedisa. (ed.), (2013), Ciudadanía, tecnología y cultura. Nodos para pensar la nueva mediación digital. Barcelona: Gedisa. (2014), "Política cultural y economía creativa en Brasil. Una perspectiva crítica de la cultura para el desarrollo local", en Revista TELOS. Cuadernos de Comunicación e Innovación, octubre de 2014 - enero de 2015, pp. 1-10 
unESCo (2013), Creative Economy Report. Widening Local Development Pathways. París: unEsCo.

Van Zoonen, L.; F. Vis y S. Minelj (2010), "Performing Citizenship on YouTube: Activism, Satire and on-line Debate Around the antiIslam video Fitna", en Critical Discourse Studies, vol. 7, no. 4. pp. 249-262.

yproductions (2009), Innovación en cultura. Madrid: Traficantes de Sueños.

YúdicE, George (2002), El recurso de la cultura. Usos de la cultura en la era global. Barcelona: Gedisa.

Fecha de recepción: 17 de octubre de 2014 Fecha de aceptación: 1 de octubre de 2015 